\title{
Differential diagnosis of acute otitis media (AOM) from secretory otitis media (SOM) through tympanometry, audiometry and diapasonic tests: reporting two cases with acute otitis media
}

\begin{abstract}
Acute Otitis Media (AOM) is an infectious disease that may be experienced by both children and adults. Among its common symptoms, we can name fever, which is due to the infectious nature of the disease, and otalgia. Secretory Otitis Media (SOM) may occur due to nasal septum deviation, sinusitis, allergies, adenoid hypertrophy, cold and dysfunction of Eustachian tube and other conditions, leading to middle ear effusion. In this study, we deal with differential diagnosis of AOM from SOM in two patients recently afflicted with AOM. It is of high importance to differentially diagnose AOM from SOM, because likelihood of occurrence of labyrinthitis in AOM is higher than in SOM due to infectious nature of AOM.
\end{abstract}

Volume 2 Issue 3 - 2015

\author{
Alireza Bina, Hamid Hosseini \\ Atieh Hospital,Audiology Clinic, Iran
}

Correspondence: Alireza Bina,Atieh Hospital,Audiology Clinic, Iran,Tel 817-666-2926, Email bina_alireza@yahoo.com

Received: January 27, 2015 | Published: April 14, 2015

Keywords: differential diagnosis, acute otitis media, secretory otitis media, hearing loss

\section{Introduction}

Differential diagnosis of Acute Otitis Media (AOM) from Secretory Otitis Media (SOM) by the tests used in this study does not apply to these conditions: 1) the patients afflicted with SOM following AOM or vice versa (the patients with both conditions), making differential diagnosis demanding; 2 ) the patients experienced perforated tympanic membrane following AOM, or experienced labyrinthitis and slight to profound sensorineural hearing loss following either AOM or SOM; 3 ) the patients with a former history of hearing loss or ear diseases before affliction with AOM or SOM; 4) the patients afflicted with AOM for a long period, not being afflicted recently; 5) Weber test is useful only in unilateral AOM or SOM cases. It is necessary to note that the cases reported in this study were the patients suffered from AOM recently and had no former history of hearing loss.

$\mathrm{AOM}$ is an infectious disease that may be experienced by both children and adults. Among its common symptoms, we can name fever, which is due to the infectious nature of the disease, and otalgia. SOM may occur due to nasal septum deviation, sinusitis, allergies, adenoid hypertrophy, cold and dysfunction of Eustachian tube and other conditions, leading to middle ear effusion.

\section{Discussion}

There may be otalgia in SOM, but it is severer and more abrupt in AOM than in SOM. In some literature, it is stated that bulging is seen in AOM, but there is retracted malleus in SOM. It was, however, observed rarely according to my clinical experience. Otoscopically, tympanic membrane is red and inflamed in $\mathrm{AOM}$, a phenomenon seen in advanced SOM, making it hard to differentially diagnose them by otoscopy. Of course, redness and inflammation is severer in AOM than in SOM.

In AOM tympanometric and otoscopic tests are not consistent; i.e. tympanic membrane is red and inflamed in otoscopy and we expect Type B in tympanometry, but we encounter Type An with good static compliance, provided that the five conditions specified earlier are met. In some AOM cases, positive pressure is seen in tympanometry. However, in many cases, positive pressure is present in tympanometry due to artifact of tympanometer or cry of the child. Presence of positive pressure in tympanometry, redness and inflammation of tympanic membrane and severe otalgia are among the symptoms of AOM. There is no positive pressure in tympanometry in some AOM cases and we have Type An tympanometry at the pressure of $0 \mathrm{daPa}$, which has been reported in case report No. 2 .

Conductive hearing loss is not seen in AOM provided that the five conditions are met, but it is present in advanced SOM due to middle ear effusion. In diapasonic or audiometric Weber Test is lateralized towards the affected ear in unilateral SOM, but it is not lateralized in the affected ear in unilateral AOM.

Weber test is one of the best tests for differential diagnosis of unilateral AOM and unilateral SOM. Rinne diapasonic test will be negative in SOM with remarkable conductive hearing loss, but it will be positive in AOM, as reported in the case reports. Ipsi and contra acoustic reflexes will be absent in AOM like in advanced SOM.

In cases where unilateral AOM leads to perforation of tympanic membrane, Weber test will be lateralized towards the affected ear due to the occlusion effect, provided that other ear is normal, and if perforated tympanic membrane and otorrhea has led to remarkable conductive hearing loss, Rinne diapasonic test will be negative. ${ }^{1-8}$

\section{Case reports}

\section{Case report I}

A 6 years old child referred to our clinic, complaining of severe left otalgia. In otoscopy, right ear was completely normal, but left tympanic membrane and malleus were completely red and inflamed. In tympanometry of right ear, there was Type An at the pressure of 0 daPa and acoustic reflexes (IPSI and contra) were present. In left ear, there was Type An tympanometry with $\mathrm{SC}=0.7 \mathrm{cc}$ at the pressure of $+50 \mathrm{daPa}$, and acoustic reflexes were absent in left ear. Diapasonic Weber test was performed three times, and it was heard in the midline. 
Audiometry indicated normal hearing in both ears. In PTA test of left ear, the child's hearing was under $0 \mathrm{~dB}$ in most frequencies. Rinne diapasonic test was performed three times, which was positive at each time.
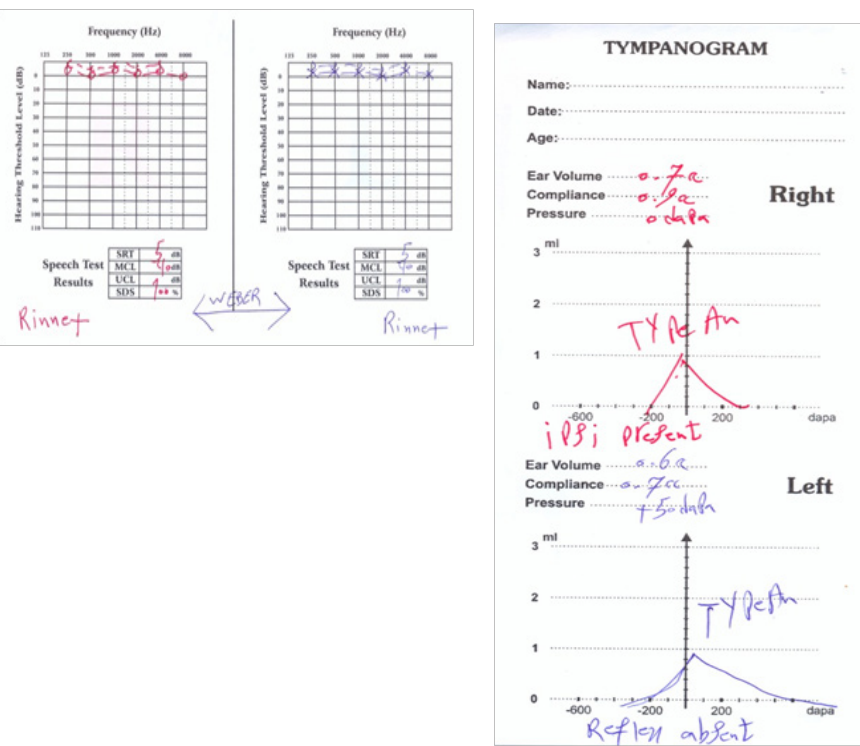

Figure I Audiogram and Tympanogram of Case No I.

Table I Comparison of AOM with SOM by audiology tests

\begin{tabular}{|l|l|l|l|l|l|l|}
\hline & Otoscopy & Tympanometry & $\begin{array}{l}\text { Acoustic } \\
\text { Reflex }\end{array}$ & Rinne Test & Weber Test & Pta Test \\
\hline $\begin{array}{l}\text { Acute Otitis } \\
\text { Media (AOM) }\end{array}$ & $\begin{array}{l}\text { Red (Bloody) } \\
\text { Tympanic } \\
\text { membrane }\end{array}$ & $\begin{array}{l}\text { Type An with Positive } \\
\text { Pressure or 0 daPa }\end{array}$ & Absent & + & $\begin{array}{l}\text { In Midline } \\
\text { or AOM } \\
\text { Opposite Ear }\end{array}$ & Normal \\
\hline $\begin{array}{l}\text { Advanced } \\
\text { Secretory Otitis } \\
\text { Media (SOM) }\end{array}$ & $\begin{array}{l}\text { Red Tympanic } \\
\text { membrane }\end{array}$ & Type B- C2-AS & Absent & - & In SOM Ear & $\begin{array}{l}\text { Conductive } \\
\text { Hearing Loss }\end{array}$ \\
\hline
\end{tabular}

Corticosteroid therapy continued by the physician for some more periods, but in the last session, the patient had sensorineural hearing loss with $\mathrm{SRT}=30 \mathrm{~dB}$, tympanic membrane was normal, the vertigo was cured, but the patient still complained of tinnitus and hyperacusis in right ear. The patient's SDS was $100 \%$ in the last session and dynamic range was $\mathrm{SRT}=30, \mathrm{UCL}=60 \mathrm{~dB}$.

\section{Conclusion}

According to this study, we could name AOM Otitis Media without effusion in the beginning of the disease. But if infection penetrate to the Tympanic Cavity result would be resembled as SOM and differential diagnosis is not possible. The following table compares AOM and SOM through different tests. The information included in the table will be applicable provided that the five conditions mentioned earlier are met.

\section{Acknowledgments}

None.

\section{Case report 2}

A 30 years old woman referred to our clinic, complaining of severe otalgia, tinnitus, hearing loss in right ear, and vertigo. The patient stated that she experienced all problems within one day. In otoscopy, right tympanic membrane and malleus were bloody in color. Otoscopy of left ear indicated normal tympanic membrane. In tympanometry test of both ears, there was Type An at the pressure of $0 \mathrm{daPa}$, and IPSI acoustic reflex was present in left ear, but absent in right ear. As mentioned earlier, inconsistency between otoscopy and tympanometry in this patient with severe otalgia is indicative of AOM, which makes diagnosis of AOM definite.

PTA test of left ear indicates normal hearing, but there was sensorineural hearing loss with SRT $=65 \mathrm{~dB}$ in right ear. Air bone gap and conductive hearing loss were not seen in right ear. Dynamic range was limited in right ear due to hyperacusis; $\mathrm{SRT}=65 \mathrm{~dB}$ and $\mathrm{UCL}=75$ $\mathrm{dB}$. The patient suffered from labyrinthitis and abrupt sensorineural hearing loss probably due to AOM.

The physician prescribed ciprofloxacin for treatment of the patient's $\mathrm{AOM}$ and corticosteroid therapy for treatment of abrupt sensorineural hearing loss. In next refer, otalgia was cured. In otoscopy, tympanic membrane was improved, but there still was redness in some parts of it. Tinnitus and vertigo were decreased. IPSI reflex of right ear, which was absent in previous session, was present. SDS of the patient's right ear was poor in the first session, which fortunately reached $76 \%$ after a cycle of corticosteroid therapy. SRT of right ear reached $45 \mathrm{~dB}$ dynamic range improved relatively, $\mathrm{SRT}=45 \mathrm{~dB}$ and $\mathrm{UCL}=60 \mathrm{~dB}$.

\section{Conflicts of interest}

The authors declare that there are no conflicts of interest.

\section{Funding}

None.

\section{References}

1. Bien J, Siegel R. Acute Otitis Media in Children: A Continuing Story. Pediatrics in Review. 2004;25(6):187-193.

2. Harrison C. How Will the New Guidelines for Managing Otitis Media Work in Your Practice? Contemporary Pediatrics. 2004;21(6):24.

3. Hendley J. Otitis media. $N$ Engl J Med. 2002;347:1169-1174.

4. Mccracken GH. Diagnosis and Management of Acute Otitis Media in Urgent Care Setting. Ann Emerg Med. 2002;39(4):413-421.

5. Jacob Sadé. Secretory Otitis Media and its Sequelae. New York, USA: Churchill Living Stone; 1979. 
6. N Shah. Otitis Media and its Sequelae. JR Soc Med. 1991;84(10):581-586

7. Roeser RJ, Valente M, Dunn HH. Audiology: Diagnosis. 2nd edn, Germany: Thieme Medical Publishers; 2008.
8. Katz J. clinical audiology. In: Medwetsky L, editor, Handbo ok of clinical audiology. 6th edn, Lippincott, Williams\&Wilkins, USA: Wolters Kluwer; 2009. 